\title{
Antibacterial action of the urease inhibitor acetohydroxamic acid on Helicobacter pylori
}

\author{
K Phillips, D J Munster, R A Allardyce, P F Bagshaw
}

\begin{abstract}
The urease inhibitor acetohydroxamic acid (AHA) was assessed for its bacteriostatic and bactericidal effects on Helicobacter pylori. For eight isolates of $H$ pylori, the minimum inhibitory concentration (MIC) was either $200 \mathrm{mg} / 1$ or 400 mg/l. Interactions between AHA and antimicrobial drugs used to treat $H$ pylori were also determined. For most isolates AHA reduced the MIC for colloidal bismuth subcitrate (CBS), tetracycline, metronidazole, and amoxicillin. In a few isolates, however, AHA increased the minimum bactericidal concentration (MBC) for these antimicrobial treatments. In vitro AHA is active against $H$ pylori and it interacts with other agents directed against $H$ pylori.
\end{abstract}

$(\Im$ Clin Pathol 1993;46:372-373)

Helicobacter pylori colonises the human stomach, causes antral gastritis, and is frequently associated with peptic ulcer disease. It produces copious amounts of the enzyme urease which protects the organism from acid. This protection is abolished in vitro by acetohydroxamic acid (AHA). ${ }^{12}$ It is not known if AHA or other urease inhibitors can be used in the treatment of $H$ pylori infections.

Opinion on the antimicrobial properties of
Department of Surgery, Christchurch School of Medicine, Private Bay, Christchurch, New Zealand

K Phillips

D J Munster

R A Allardyce

P F Bagshaw

Correspondence to:

Accepted for publication

4 November 1992
Dr K Phillips
AHA varies. ${ }^{1}$ It has been reported to be bacteriostatic for several organisms, ${ }^{3}$ including $H$ pylori, ${ }^{4}$ and that it acts synergistically with antimicrobial drugs directed against urease producing organisms other than $\mathrm{H}_{\text {pylori. }}{ }^{5}$ Others, however, have found that AHA has no effect on $H$ pylori. ${ }^{67}$ We now report our findings on the bacteriostatic and bactericidal effects of AHA on $H$ pylori, and on the interactions between AHA and antimicrobial drugs used to treat the infection.
Effect of AHA on MICs and MBCs of antimicrobial drugs

\begin{tabular}{llllll}
\hline & \multicolumn{2}{l}{$M I C$} & & & $M B C$ \\
\cline { 6 - 7 } \cline { 5 - 6 } \cline { 5 - 6 } & Decreased & Increased & & Decreased & Increased \\
\hline CBS & $8 / 8$ & $0 / 8$ & & $0 / 7$ & $2 / 7$ \\
Tetracycline & $5 / 8$ & $0 / 8$ & & $1 / 6$ & $3 / 6$ \\
Metronidazole & $7 / 8$ & $0 / 8$ & & $3 / 8$ & $1 / 8$ \\
Amoxicillin & $6 / 7$ & $0 / 7$ & & $1 / 7$ & $1 / 7$ \\
\hline
\end{tabular}

AHA $=50$ or $100 \mathrm{mg} / \mathrm{l}$. The table shows the number of isolates affected over the number tested.

\section{Methods}

$H$ pylori type strain NCTC 11637 and seven clinical isolates were used for all experiments. Minimum inhibitory and bactericidal concentrations (MIC) (MBC) were determined as described previously. ${ }^{8}$ Serial doubling dilutions of colloidal bismuth subcitrate (CBS, Gist-Brocades, the Netherlands), tetracycline (Sigma Chemical Co., St Louis, Missouri, USA), metronidazole (Sigma), amoxicillin (Sigma), and AHA (Sigma) were made in $1 \mathrm{ml}$ of brucella broth (Difco) with $10 \%$ fetal bovine serum. $H$ pylori, grown for three days in a microaerobic atmosphere on Colombia sheep blood agar, was suspended in broth (about $3 \times 10^{6} \mathrm{cfu} / \mathrm{ml}$ ). One millilitre of this bacterial suspension was added to each antimicrobial dilution and to broth without antibiotic. These were incubated for three days in the microaerobic atmosphere. The MIC was defined as the lowest concentration of antimicrobial drug preventing visible growth.

All bottles without visible growth were subcultured on to blood agar plates. The MBC was defined as the lowest concentration of antimicrobial drug that prevented growth on these plates after incubation for three days.

Interactions between AHA and antimicrobial drugs were investigated by performing serial doubling dilutions of each antimicrobial drug in broth containing a subinhibitory concentration of AHA (0.25 × MIC of AHA for each isolate).

\section{Results}

AHA was inhibitory for all isolates and bactericidal for seven of eight isolates of $H$ pylori tested. The MIC was either $200 \mathrm{mg} / 1$ (two isolates) or $400 \mathrm{mg} / \mathrm{l}$ (six isolates). The MBC was $400 \mathrm{mg} / 1$ (three isolates), $800 \mathrm{mg} / 1$ (three isolates), or $1600 \mathrm{mg} / \mathrm{l}$ (one isolate).

MICs and MBCs for CBS, tetracycline, metronidazole, and amoxicillin overlapped previously reported ranges. ${ }^{8}$

Subinhibitory concentrations of AHA caused a two- or more-fold reduction in MIC for CBS in all eight isolates (table). For most isolates, AHA also reduced the MIC for tetracycline, metronidazole, and amoxicillin (table). The MIC was not increased by AHA.

For some isolates, AHA caused a reduction in $\mathrm{MBC}$ for tetracycline, metronidazole, and amoxicillin. For a few isolates, the MBC was increased for all four antimicrobial drugs (table). 


\section{Discussion}

AHA is both bacteriostatic and bactericidal for $H$ pylori in broth culture, in agreement with the findings of Glupczynski et al. ${ }^{4}$ The negative findings of other workers may reflect methodological differences. ${ }^{67}$

For most isolate/antimicrobial combinations, subinhibitory concentrations of AHA affected the activity of the antimicrobial drug (table). Although a reduction in MIC for each antimicrobial drug was the rule, these were rarely large, with greater than four-fold reductions occurring only three times. Glupczynski et al observed such synergy between AHA and tetracycline and metronidazole for some isolates. ${ }^{4}$ Like us, they did not observe any antagonistic effect.

In contrast, we found that MBCs were increased by AHA for seven of 28 isolates/antimicrobial combinations (table), although none of these increases was more than four-fold. MBCs were reduced by AHA for only five of the 28 combinations.

The mechanisms of action of AHA, either alone or in conjunction with antimicrobial drugs, in broth culture at neutral $\mathrm{pH}$, are unknown. At concentrations higher than $1000 \mathrm{mg} / \mathrm{l}$, AHA is bacteriostatic to some organisms that do not produce urease. ${ }^{3}$ This non-urease mechanism may also work for $H$ pylori. $H$ pylori urease is, however, inhibited in vitro at lower concentrations ${ }^{7} ; 50 \%$ inhibition occurs at $100 \mathrm{mg} / 1^{6}$; and synergistic interactions with antimicrobial drugs also occur at this concentration (table). In vivo a single $750 \mathrm{mg}$ dose of AHA inhibits $H$ pylori urease in infected patients by $86 \% .{ }^{9}$

Animal models of Helicobacter infection may be useful in further investigations into the clinical potential of urease inhibitors. It is already known that urease inhibitors alone do not clear existing Helicobacter infections. ${ }^{1011}$ No animal studies, nowever, have combined urease inhibitors with antimicrobial drugs.

1 Mooney C, Munster DJ, Bagshaw PF, Allardyce RA. Helicobacter pylori acid resistance. Lancet 1990;335: 1232.

2 Veldhuysen van Zanten SJO, Goldie J, Hunt RH. Inhibition of Helicobacter pylori urease by acetohydroxamic acid. Lancet 1990;336:1584.

3 Griffith DP, Musher DM, Campbell JW. Inhibition of bacterial urease. Invest Urol 1973;11:234-8.

4 Glupczynski Y, Goutier S, Labbe M. In vitro interaction between bismuth subcitrate, omeprazole, urease between bismuth subcitrate, omeprazole, urease Helicobacter pylori. Gastroenterology 1991;100:A583.

5 Musher DM, Saenz C, Griffith DP. Interaction between acetohydroxamic acid and 12 antibiotics against 14 Gram-negative pathogenic bacteria. Antimicrobial Agents Chemother 1974;5:106-10.

6 Mobley HLT, Cortesia MJ, Rosenthal LE, Jones BD. Characterisation of urease from Campylobacter pylori. $\mathcal{F}$ Clin Microbiol 1988;26:831-6.

7 Goldie J, Veldhuyzen van Zanten SJO, Jalali S, Richardson H, Hunt RH. Inhibition of urease activity but not growth of Helicobacter pylori by acetohydroxamic acid. $\mathcal{f}$ Clin Pathol 1991;44:695-7.

8 Goodwin CS, Blake P, Blincow E. The minimum inhibitory and bactericidal concentrations of antibiotics and anti-ulcer agents against Campylobacter pyloridis. $\mathcal{F}$ Antimicrobial Chemother 1986;17:309-14.

9 El Nujumi AM, Dorrian CA, Chittajullu RS, Niethercut WD, McColl KEL. Effect of inhibition of Helicobacter pylori urease activity by acetohydroxamic acid on serum gastrin in duodenal ulcer subjects. Gut 1991;32:866-70.

10 McColm AA, Bagshaw J, O'Malley C, McLaren A. Is urease a lethal target for therapy of Helicobacter pylori? Microbial Ecology in Health and Disease 1991;4:S145.

11 Ferrero $R$, Lee A. The importance of urease in acid protection for the gastric-colonising bacteria Helicobacter pylori and Helicobacter felis sp. nov. Microbial Ecology in Health and Disease 1991;4:121-34. 